\title{
DETERMINASI JAMINAN LAYANAN DAN PERCEIVED QUALITY TERHADAP KEPUASAN KONSUMEN PENGGUNA JASA BENGKEL HONDA AHASS 0501
}

\author{
Ilfam Yaksi ${ }^{1}$, Kokom Komariah ${ }^{2}$, Asep M. Ramdan ${ }^{3}$ \\ Univesitas Muhammadiyah Sukabumi ${ }^{1,2,3}$ \\ ilfamyaksi23@gmail.com ${ }^{1}$
}

\begin{abstract}
ABSTRAK
Tujuan penelitian ini adalah untuk mengetahui pengaruh jaminan dan perceived quality terhadap kepuasaan konsumen pada bengkel AHASS 0501. Metode penelitian ini menggunakan jenis sampling termasuk ke dalam sampel random sampling. Teknik analisis yang digunakan adalah teknik analisis linear berganda, dan untuk pengujian hipotesis adalah uji secara simultan (uji f). Berdasarkan uji koefisien determinasi sebesar 0,868 dapat diartikan bahwa pengaruh jaminan layanan dan perceived quality terhadap kepuasan konsumen adalah sebesar 75,3\%. Sisanya 24,7\% dipengaruhi oleh faktor lainnya yang tidak djelaskan dalam penelitian ini. Berdasarkan uji $\mathrm{f}$ yang dilakukan, diperoleh nilai probabilitas sig. $0,000<0,05$ dan perhitungan uji $\mathrm{F}$ menunjukkan bahwa F hitung lebih besar dari F tabel yaitu $129.777>2,37$. Simpulan, Jaminan Layanan (X1) dan Perceived Quality (X2) berpengaruh signifikan terhadap Kepuasan Konsumen (Y).
\end{abstract}

Kata Kunci : Jaminan, Persepsi Kualitas, Kepuasan Konsumen

\begin{abstract}
The purpose of this study was to determine the effect of collateral and perceived quality on consumer satisfaction at AHASS 0501. Workshop This research method uses the type of sampling included in the random sampling sample. The analysis technique used is multiple linear analysis techniques, and for testing the hypothesis is a simultaneous test ( $f$ test). Based on the coefficient of determination test of 0.868 can be interpreted that the effect of service assurance and perceived quality on customer satisfaction is $75.3 \%$. The remaining $24.7 \%$ is influenced by other factors not explained in this study. Based on the $f$ test, a probability value of sig is obtained. 0,000 $<0.05$ and the F test calculation shows that the F count is greater than the F table which is 129,777> 2.37. Conclusions, Service Guarantee (X1) and Perceived Quality (X2) have a significant effect on Consumer Satisfaction ( $Y)$.
\end{abstract}

Keywords: Guarantee, Quality Perception, Consumer Satisfaction 


\section{PENDAHULUAN}

Perkembangan dunia otomotif yang semakin pesat, masyarakat tentunya sangat membutuhkan alat transportasi baik darat maupun laut dengan cepat dapat melayani kebutuhan pengguna kendaraan. Salah satu contoh kendaraan yang paling diminati oleh masyarakat adalah kendaraan roda dua atau sering disebut sepeda motor, hal ini dapat dilihat betapa maraknya pengguna sepeda motor dan tak bisa dipungkiri salah satu penyebab terjadinya kemacetan ialah sepeda motor itu sendiri. Kendaraan roda dua atau sepeda motor yang diminati oleh masyarakat terutama remaja adalah motor bertipe sport dan automatic, dan ini tercatat di tahun 2017 motor tipe automatic yang paling laris dengan penjualan $82 \%$, tipe sport $9.20 \%$, dan tipe bebek $8.43 \%$, tentunya sepeda motor tersebut memerlukan perawatan yang berkala supaya kendaraan tetap awet juga stylist. Dengan banyaknya pengguna sepeda motor, maka dari itu banyak pula peluang pekerjaan baik itu sebagai pemilik atau pekerja mulai dari dealer, showroom kendaraan, sampai usaha bengkel kendaraan roda dua.

Sekarang ini banyak sekali bengkel-bengkel yang berdiri di Indonesia baik itu bengkel resmi mataupun bengkel. Dalam kondisi ini kendaraan bermotor memerlukan perawatan serta perbaikan yang tentunya harus dilakukan secara berkala agar masa pakai kendaraan lebih lama. Honda sebagai salah satu produsen kendaraan bermotor terbesar di Indonesia, khususnya bengkel Astra Honda Autorizhed Service Station (AHASS) 0501 kota Sukabumi tidak hanya dituntut untuk memenuhi pelayanan dengan baik, tetapi harus mempertahankan kelangsungan hidup perusahaan dengan memberikan pelayanan terutama dalam jaminan servis kendaraan yang dilakukan bengkel Honda agar senantiasa konsumen merasa puas dengan hasil yang telah ia dapatkan dari pelayanan yang diberikan oleh pelayanan bengkel.

Kepuasan konsumen aset yang sangat penting bagi kelangsungan perusahaan terutama pada industry otomotif. Banyaknya topik penelitian mengenai kepuasan konsumen, peneliti mengkaji 10 tahun terakhir (Wisnalmawati, 2008; Istianto, John, \& Tyra, 2011; Nugroho, 2016). Kepuasan konsumen merupakan perasaan senang atau kecewa seseorang yang muncul setelah membandingkan kinerja (hasil) produk yang diharapkan terhadap kinerja yang dirasakan (Kotler dan Keller, 2016). Konsumen akan melakukan evaluasi terhadap produk atau jasa yang dirasakan apakah bisa memenuhi apa yang diharapkannya. 
Perceived Quality menurut David A. Aaker dalam Sopiah, Sangadji (2016) menyatakan bahwa "persepsi konsumen terhadap keseluruhan kualitas atau keunggulan suatu produk atau jasa layanan berkaitan dengan maksud yang diharapkan".persepsi kualitas merupakan persepsi dari konsumen terhadap keseluruhan kualitas atau keunggulan suatu produk atau jasa berkaitan dengan harapan konsumennya

Jaminan merupakan pengetahuan, kemampuan, kesopanan dan sifat dapat dipercaya yang dimiliki para staf, bebas dari bahaya, resiko atau keraguan (Tjiptono dalam Permana, 2013). Jaminan juga berarti bahwa para karyawannya selalu bersikap sopan dan menguasai keterampilan yang dibutuhkan untuk menangani setiap pertanyaan atau masalah konsumen.

Tema yang diusulkan peneliti adalah Determinasi Jaminan Servis dan Perceived Quality Terhadap Kepuasan Konsumen Pengguna Jasa Bengkel AHASS 0501 Kota Sukabumi. Tujuan penelitian ini adalah untuk mengetahui bagaimana pengaruh jaminan dan perceived quality terhadap kepuasan konsumen.

\section{KAJIAN TEORI}

Menurut Tjiptono dalam Permana (2013) Jaminan merupakan pengetahuan, kemampuan, kesopanan dan sifat dapat dipercaya yang dimiliki para staf, bebas dari bahaya, resiko atau keraguan. Jaminan merupakan pengetahuan, kesopanan, dan kemampuan para pegawai perusahaan untuk menumbuhkan rasa percaya konsumen kepada perusahaan dan hal ini meliputi beberapa komponen antara lain:

1. Kredibilitas. Adalah keadaan dimana kondisi yang dapat dipercaya dan bisa dipertanggung jawabkan sebagaimana seharusnya.

2. Keamanan. Dalam arti bahwa proses serta hasil pelayanan dapat memberikan keamanan serta dapat memberikan kepastian.

3. Kompetensi. Adalah keandalan atau kemampuan yang dimiliki seseorang untuk menunjukan dan mengaplikasikan dalam tugasnya sesuai standar.

4. Sopan santun karyawan. Peraturan yang harus dipatuhi oleh setiap karyawan untuk melayani konsumen dengan ramah, supaya konsumen merasa nyaman atas pelayanan yang diberikan perusahaan. 
Perceived Quality adalah persepsi konsumen terhadap keseluruhan kualitas atau keunggulan suatu produk atau jasa layanan berkaitan dengan apa yang diharapkan oleh konsumen berdasarkan kepentingannya (Durianto dalam Rahmatina et al, 2016).

Menurut Durianto dalam Rahmatina et al, (2016) dimensi dari perceived quality terdiri dari 7 yaitu:

1. Kinerja, yaitu melibatkan berbagai karakteristik operasional utama.

2. Pelayanan, yaitu mencerminkan kemampuan karyawan dalam memberikan pelayanan.

3. Ketahanan, yaitu mencerminkan umur ekonomis dari produk atau jasa tersebut.

4. Keandalan, yaitu konsistensi dari kinerja yang dihasilkan suatu produk atau layanan satu kali pembelian ke pembelian berikutnya meningkat.

5. Karakteristik, yaitu merupakan tambahan untuk menjadi pembeda bahwa perusahaan memahami kebutuhan konsumen yang dinamis.

6. Kesesuaian dengan spesifikasi, merupakan pandangan mengenai kualitas produk atau pelayanan sesuai dengan spesifikasi yang telah teruji.

7. Hasil, yaitu mengarah kepada kualitas yang dirasakan melibatkan enam dimensi sebelumnya. Jika perusahaan tidak menghasilkan hasil akhir produk atau jasa yang baik maka kemungkinan produk atau jasa tersebut tidak akan mempunyai atribut kualitas yang penting.

Kepuasan konsumen adalah perasaan senang atau kecewa seseorang yang muncul setelah membandingkan antara kinerja (hasil) produk yang dipikirkan terhadap kinerja yang diharapkan (Kotler, Keller, 2009).

Adapun dimensi kepuasan konsumen menurut Hawkins dan Lonney dalam Tjiptono (2014) adalah :

1. Kesesuaian Harapan Yaitu tingkat kesesuaian harapan antara kinerja produk yang diharapkan oleh konsumen dengan apa yang dirasakan oleh konsumen, meliputi:

a. Produk yang diperoleh sesuai atau melebihi dari apa yang diharapkan.

b. Pelayanan oleh karyawan yang diperoleh sesuai atau melebihi dari apa yang diharapkan.

c. Fasilitas penunjang yang didapat sesuai melebihi dengan apa yang diharapkan. 
2. Minat Berkunjung Kembali

Yaitu kesediaan konsumen untuk berkunjung kembali atau melakukan pembelian ulang terhadap produk tersebut, meliputi :

a. Berminat berkungjung kembali karena pelayanan yang diberikan oleh karyawan memuaskan.

b. Berminat berkunjung kembali karena nilai dan manfaat yang diperoleh setelah mengkonsumsi produk.

c. Berminat berkunjung kembali karena fasilitas penunjang yang disediakan memadai.

3. Kesediaan Merekomendasikan

Yaitu kesediaan konsumen untuk merekomendasikan produk yang telah dirasakannya kepada teman atau keluarga, meliputi :

a. Menyarankan teman atau kerabat untuk membeli produk yang ditawarkan karena pelayanan memuaskan.

b. Menyarankan teman atau kerabat untuk membeli produk yang ditawarkan karena fasilitas penunjang yang disediakan memadai.

\section{METODE PENELITIAN}

Penelitian ini dilaksanakan di AHASS 0501 Kota Sukabumi.Metode dalam penelitian ini adalah menggunakan jenis sampling termasuk kedalam sampel random sampling dan dengan melakukan penyebaran kuesioner sebanyak 88 kepada konsumen. Teknik analisis yang digunakan adalah teknik analisis regresilinear berganda, dan untuk pengujian hipotesis adalah uji statistik secara simultan (uji f).

Penelitian yang dijadikan variabel bebas adalah jaminan dan perceived quality. Jaminan memiliki 4 dimensi yaitu :kredibilitas, keamanan, kompetensi dan sopan santun karyawan. Perceived Quality memiliki 7 dimensi yaitu : kinerja, pelayanan, ketahanan, keandalan, karakteristik, kesesuaian dengan spesifikasi dan hasil. Dan yang menjadi variabel variabel terikat adalah kepuasan konsumen dengan dimensi sebagai berikut : kesesuaian harapan, minat berkunjung kembali dan kesediaan merekomendasikan. 


\section{HASIL PENELITIAN}

\section{Uji Validitas}

Uji validitas adalah alat ukur untuk mengukur apa yang seharusnya diukur sehingga suatu penelitian yang menggunakan kuesioner sebagian besar pengukurnya perlu diuji validitasnya. Syarat minimum untuk dianggap memenuhi syarat adalah $r=$ 0,3. Jadi jika korelasi antara butir dengan dengan skor total kurang dari 0,3 maka butir dengan instrument dinyatakan tidak valid.

Berdasarkan pengujian validitas menggunakan bantuan software SPSS 24 diperoleh hasil sebagai berikut :

Tabel 1 Jaminan X1

\begin{tabular}{cccc}
\hline Item & r Hitung & R Kritis & Keterangan \\
\hline 1 & 0.754 & 0,3 & Valid \\
2 & 0,733 & 0,3 & Valid \\
3 & 0,772 & 0,3 & Valid \\
4 & 0,638 & 0,3 & Valid \\
\hline
\end{tabular}

Sumber : Data Primer (Kuesioner) 2019

Berdasarkan tabel 1 menunjukkan bahwa semua item pernyataan pada variabel jaminan valid dengan masing-masing nilai $\mathrm{r}$ hitung untuk item 10,754 , item 20,733 , item 3 0,772 dan item $40,639$.

Tabel 2 Perceived Quality X2

\begin{tabular}{cccc}
\hline Item & r Hitung & R Kritis & Keterangan \\
\hline 1 & 0.779 & 0,3 & Valid \\
2 & 0,688 & 0,3 & Valid \\
3 & 0,581 & 0,3 & Valid \\
4 & 0,623 & 0,3 & Valid \\
5 & 0,777 & 0,3 & Valid \\
6 & 0,651 & 0,3 & Valid \\
7 & 0,862 & 0,3 & Valid \\
\hline
\end{tabular}

Sumber : Data Primer (Kuesioner) 2019

Berdasarkan tabel menunjukkan bahwa semua item pernyataan pada variabel perceived quality valid dengan masing-masing nilai $r$ hitung untuk item 10,7779 , item 2 0,688, item 3 0,581, item 4 0,623, item 5 0,777, item 60 , 651 dan item 70,862 .

Tabel 3 Kepuasan Konsumen Y

\begin{tabular}{cccc}
\hline Item & r Hitung & R Kritis & Keterangan \\
\hline 1 & 0.933 & 0,3 & Valid \\
2 & 0,836 & 0,3 & Valid \\
3 & 0,900 & 0,3 & Valid \\
\hline
\end{tabular}

Sumber : Data Primer (Kuesioner) 2019 
Berdasarkan tabel 1 menunjukkan bahwa semua item pernyataan pada variabel kepuasan konsumen Y valid dengan masing-masing nilai $r$ hitung untuk item 1 0,933, item 20,836 , dan item $30,900$.

\section{Uji Reliabilitas}

Hasil uji reliabilitas dengan menggunakan rumus Cronbach's Alpha dengan bantuan SPSS 24 adalah sebagai berikut :

Tabel 4 Hasil Uji Reliabilitas

\begin{tabular}{cccc}
\hline Variabel & \multicolumn{2}{c}{ Koefisien Cronbach's Alpha } & \multirow{2}{*}{ Keterangan } \\
\cline { 2 - 3 } & Hitung & Standar & \\
\hline Jaminan X1 & 0,788 & 0,6 & Reliabel \\
\hline Perceived Quality X2 & 0,776 & 0,6 & Reliabel \\
\hline $\begin{array}{c}\text { Kepuasan Konsumen } \\
\text { Y }\end{array}$ & 0,858 & 0,6 & Reliabel \\
\hline
\end{tabular}

Sumber : Data Primer (Kuesioner), 2019

Berdasarkan tabel diatas dapat dilihat bahwa untuk variabel jaminan X1, perceived quality $\mathrm{X} 2$ dan kepuasan konsumen $\mathrm{Y}$ reliabel.

\section{Koefisien Korelasi Ganda}

Untuk melakukan teknik analisis, peneliti menggunakan bantuan perangkat lunak SPSS 24.

Tabel 5 Koefesien Korelasi antara Jaminan (X1), Perceived Quality (X2) dan Kepuasan Konsumen (Y)

\begin{tabular}{lcccc}
\hline \multicolumn{4}{c}{ Model Summary } \\
\hline Model & $\mathrm{R}$ & R Square & Adjusted R Square & Std. Error of the Estimate \\
\hline 1 & $.868^{\mathrm{a}}$ & .753 & .748 & 1.197
\end{tabular}

a. Predictors: (Constant), X2, X2

Berdasarkan perhitungan di atas, dapat diketahui bahwa korelasi variabel jaminan dan perceived quality adalah sebesar 0,868 (lihat nilai $\mathrm{R}$ pada tabel di atas).

\section{Koefisien Determinasi}

$$
K d=r^{2} \times 100 \%
$$


Dimana:

$K d=r^{2} \times 100 \%$

Dimana :

$\mathrm{Kd}=$ koefisien determinasi

$\mathrm{r}=$ koefisien kolerasi

Diketahui :

$\mathrm{r}=0,868$

$\mathrm{Kd}=(0,868)^{2} \times 100 \%$

$\mathrm{Kd}=0,753 \times 100 \%$

$\mathrm{Kd}=75,3 \%$

Berdasarkan perhitungan koefisien determinasi yang telah peneliti lakukan, diketahui bahwa nilai $\mathrm{Kd}=75,3 \%$. Maka dapat disimpulkan bahwa pengaruh Jaminan Servis dan Perceived Quality terhadap Kepuasan Konsumen yaitu kuat.

Perhitungan regresi ganda dilakukan dengan penggunaan software SPSS 24, adapun hasilnya yaitu sebagai berikut:

\section{Regresi Linier Berganda}

Tabel 6 Hasil Perhitungan Regresi Ganda

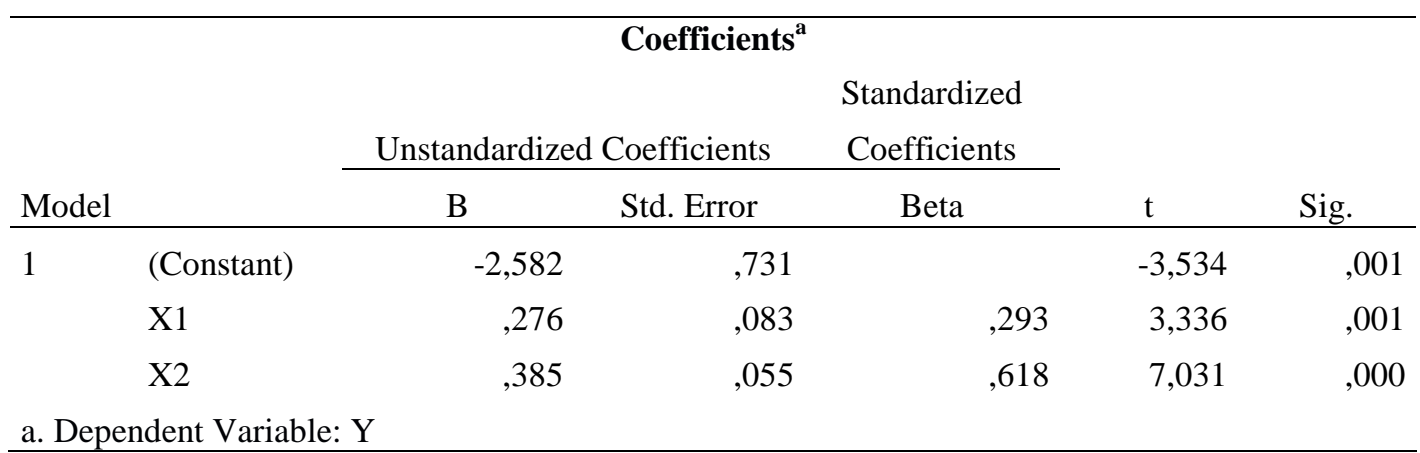

Dari hasil diatas, dapat diketahui persamaan regresi linear berganda yaitu:

$\mathrm{b}_{1}=0,293$

$\mathrm{b}_{2}=0,618$

Selanjutnya didapat persamaan regresi linier berganda untuk dua prediktor yaitu jaminan layanan dan perceived quality adalah sebagai berikut :

$$
Y^{*}=0,293 \mathrm{X}_{1}+0,618 \mathrm{X}_{2}+\mu
$$


Berdasarkan dari hasil persamaan di atas dapat diketahui bahwa terdapat pengaruh yang positif antara Jaminan Layanan (x1) dan Perceived Quality (x2) terhadap Kepuasan Konsumen (y). Persamaan tersebut menunjukan bahwa Kepuasan Konsumen pada bengkel AHASS 0501 Kota Sukabumi akan meningkat apabila Jaminan Layanan dan Perceived Quality ditingkatkan. Adapun koefisien regresi untuk Jaminan Layanan sebesar 0,293 lebih kecil daripada koefisien regresi untuk Perceived Quality sebesar 0,618 .

\section{Uji Signifikasi Secara Simultan (Uji F)}

Tabel 7 Hasil Uji F

\begin{tabular}{|c|c|c|c|c|c|c|}
\hline \multicolumn{7}{|c|}{ ANOVA $^{a}$} \\
\hline Model & & Sum of Squares & df & Mean Square & $\mathrm{F}$ & Sig. \\
\hline \multirow[t]{3}{*}{1} & Regression & 372,133 & 2 & 186,066 & 129,777 &, $000^{\mathrm{b}}$ \\
\hline & Residual & 121,867 & 85 & 1,434 & & \\
\hline & Total & 494,000 & 87 & & & \\
\hline \multicolumn{7}{|c|}{ a. Dependent Variable: Y } \\
\hline \multicolumn{7}{|c|}{ b. Predictors: (Constant), X2, X1 } \\
\hline
\end{tabular}

Berdasarkan data diatas, di dapatkan hasil $\mathrm{F}$ hitung variable $\mathrm{X} 1$ ( jaminan servis), X2 (perceived quality) dan Y (kepuasan konsumen) adalah sebesar 129.777 selanjutnya nilai $\mathrm{F}$ hitung tersebut dibandingkan dengan nila $\mathrm{F}$ tabel. $\mathrm{F}$ tabel dicari pada tabel yang tertera pada lampiran dengan didasarkan pada $\mathrm{dk}$ pembilang $=\mathrm{k}$ dan $\mathrm{dk}$ penyebut $=(\mathrm{n}-\mathrm{k}-1)=88-2-1=85$. dan taraf kesalahan yang ditetapkan. Adapun taraf kesalahan yang diteraapkan adalah sebesar $10 \%$. Jadi $\mathrm{dk}$ pembilang $=2$, dan $\mathrm{dk}$ penyebut $=85$, sehingga diperoleh nilai $\mathrm{F}$ tabel $=2,37$.

Berdasarkan hasil perhitungan tabel Anova diatas, nampak jelas bahwa $\mathrm{F}$ hitung lebih besar dari $\mathrm{F}$ tabel $(129.777>2,37)$ sehingga hasil pengujian hipotesis adalah sebagai berikut : $129.777>2,37$ artinya terdapat pengaruh yang positif dan signifikan antara jaminan dan perceived quality terhadap kepuasan konsumen.

\section{PEMBAHASAN}

Menurut Baharudin, (2012) menyatakan bahwa "jaminan (assurance) berpengaruh signifikan terhadap kepuasan konsumen. Dalam penelitian tersebut dijelaskan bahwa jaminan layanan yang baik akan meningkatkan kepuasan konsumen”. 
Menurut Parasuraman, Zeitamhl, dan Berry (dalam Fibriyanti, Dharmayanti, 2014), menyatakan bahwa "perceived quality mempengaruhi kepuasan konsumen. Terdapat berbagai usaha yang dilakukan oleh perusahaan untuk membuat konsumen yang dilayani merasa puas dan dapat menjadikan konsumen tersebut loyal".

Adapun 5 faktor utama untuk mengukur tingkat kepuasan konsumen (Irawan, 2003), antara lain sebagai berikut :

\section{Kualitas Produk}

Konsumen atau pelanggan akan merasa puas jika hasil evaluasi menunjukkan bahwa produk yang mereka gunakan berkualitas.

\section{Kualitas Pelayanan}

Konsumen akan merasa puas apabila mereka mendapatkan pelayanan yang baik atau yang sesuai dengan yang diharapkan.

\section{Emosional}

Konsumen yang merasa bangga dan mendapatkan keyakinan bahwa orang lain akan kagum terhadap dia bila menggunakan produk dengan merek tertentu akan cenderung mempunyai tingkat kepuasan yang lebih tinggi. Kepuasannya bukan karena kualitas dari produk tersebut tetapi self esteem atau social value yang membuat konsumen menjadi puas terhadap merek produk tertentu.

\section{Harga}

Produk yang mempunyai kualitas yang sama tetapi menetapkan harga yang relatif murah akan memberikan value yang lebih tinggi kepada konsumennya. Jelas bahwa faktor harga juga merupakan faktor yang penting bagi konsumen untuk mengevaluasi tingkat kepuasannya.

\section{Biaya dan kemudahan untuk mendapatkan produk atau jasa.}

Berdasarkan hipotesis, menyatakan bahwa Jaminan dan Perceived Quality berpengaruh terhadap Kepuasan Konsumen. Hal ini dibuktikan melalui hasil Uji $\mathrm{F}$ (simultan), didapatkan hasil $\mathrm{F}$ hitung variabel X1(jaminan), X2 (perceived quality) dan Y (kepuasan konsumen) adalah sebesar 129.777 selanjutnya nilai $\mathrm{F}$ hitung tersebut dibandingkan dengan nilai $\mathrm{F}$ tabel. Dengan didasarkan pada $\mathrm{dk}$ pembilang $=\mathrm{k}$ dan $\mathrm{dk}$ penyebut $=(\mathrm{n}-\mathrm{k}-1)=88-2-1=85$. dan taraf kesalahan yang ditetapkan. Adapun taraf kesalahan yang diterapkan adalah sebesar $10 \%$. Jadi $\mathrm{dk}$ pembilang $=2$, dan $\mathrm{dk}$ penyebut $=85$, sehingga diperoleh nilai $\mathrm{F}$ tabel $=2,37$. 
Berdasarkan hasil perhitungan tabel Anova, nampak jelas bahwa F hitung lebih besar dari F tabel (129.777 > 2,37) sehingga hasil pengujian hipotesis adalah sebagai berikut : $129.777>2,37$ artinya terdapat pengaruh yang signifikan antara jaminan dan perceived quality terhadap kepuasan konsumen.

Perceived Quality menurut David A. Aaker dalam Sopiah, Sangadji (2016) menyatakan bahwa "persepsi konsumen terhadap keseluruhan kualitas atau keunggulan suatu produk atau jasa layanan berkaitan dengan maksud yang diharapkan”.persepsi kualitas merupakan persepsi dari konsumen terhadap keseluruhan kualitas atau keunggulan suatu produk atau jasa berkaitan dengan harapan konsumennya

Jaminan merupakan pengetahuan, kemampuan, kesopanan dan sifat dapat dipercaya yang dimiliki para staf, bebas dari bahaya, resiko atau keraguan (Tjiptono dalam Permana, 2013). Jaminan juga berarti bahwa para karyawannya selalu bersikap sopan dan menguasai keterampilan yang dibutuhkan untuk menangani setiap pertanyaan atau masalah konsumen.

\section{SIMPULAN}

Setiap indikator dari masing-masing variabel Jaminan (X1), Perceived Quality (X2) dan Kepuasan Konsumen (Y) dalam penelitian ini dapat mewakili dari masingmasing variabelnya dan sekaligus dapat diandalkan untuk dipergunakan sebagai indikator dapat digunakan oleh peneliti yang akan datang.Berdasarkan Uji F, variabel jaminan dan perceived quality berpengaruh signifikan secara bersama-sama (simultan) terhadap kepuasan konsumen pengguna bengkel AHASS 0501 Kota Sukabumi.

\section{DAFTAR PUSTAKA}

Baharudin, B., Indriani, F. (2012). Analisis Pengaruh Keandalan, Jaminan dan Daya Tanggap Terhadap Kepuasan Konsumen Dalam Menggunakan Jasa PT. APEX Semarang. Skripsi: Universitas Diponegoro Semarang

Basu, S., Irawan, I. (2003). Manajemen Pemasaran Modern. Yogyakarta: Liberty Yogyakarta

Fibriyanti, F., Dharmayanti, D. (2014). Pengaruh Brand Image dan Perceived Quality terhadap Kepuasan dan Loyalitas Pelanggan mobil Toyota di Surabaya. Jurnal Manajemen Pemasaran Petra, 2(1), 1-8

Istianto, J. H., Tyra, M. J. (2011). Analisis Pengaruh Kualitas Layanan terhadap Kepuasan Pelanggan Rumah Makan Ketty Resto.Jurnal Ekonomi dan Informasi Akuntansi (Jenius), 1(3), 275-290 
Kotler, P., Keller, K. L. (2009). Manajemen Pemasaran. Jilid I. Edisi ke 13 Jakarta: Erlangga

Kotler, P., Keller, K. L. (2016). Marketing Management. 15th Edition, Person Education, Inc

Nugroho, M. (2016). Pengaruh Service Quality terhadap Kepuasan Konsumen Honda Utama Motor Yogyakarta. Universitas Negeri Yogyakarta

Permana, H., Dian, P. (2013). Faktor-Faktor yang Mempengaruhi Kualitas Pelayanan Terhadap Loyalitas Pelanggan Kereta Api Kaligung Mas (Studi Pada Stasiun Besar Pekalongan). http://eprints.dinus.ac.id/id/eprint/5067

Rahmanita, M., Saryadi, S., Listyorini, S. (2016). Pengaruh Brand Image dan Perceived Quality terhadap Loyalitas Pelanggan Melalui Kepuasan Konsumen sebagai Variabel Intervening. Jurnal Ilmu Administrasi Bisnis, 5(1). https://ejournal3.undip.ac.id/index.php/jiab/article/view/10399/10101

Sopiah, S., Sangadji, S. (2016). Salesmanship (Kepenjualan). Jakarta PT: Bumi Aksara Tjiptono, F.,.(2014). Pemasaran Jasa. Yogyakarta: Andi Offset.

Wisnalmawati, W. (2008). Kepuasan Konsumen Bengkel Motor AHASS 1605 Seturan Yogyakarta Berdasarkan Dimensi Mutu Pelayanan. Jurnal Ilmiah Ekonomi Bisnis, 13(3), 189-200 